\title{
DIABETES
}

\section{Antibiotics promote T1DM in mice}

Antibiotic treatment early in life could disrupt the gut microbiota and promote the development of type 1 diabetes mellitus (T1DM), according to a new study in mice.

The gut microbiota are important for early metabolic and immunological development, and the perturbation of microbiota in pregnancy and early childhood has been linked to illnesses such as obesity, asthma and allergies. An association has also been implicated between T1DM and early-life use of antibiotics; however, whether this effect is protective or pathogenic is unclear.

"All antibiotics do not have equal effects on the microbiome, and dose and timing are clearly important," argues corresponding author Martin Blaser. The team, therefore, studied the effect of antibiotic treatment that mimicked therapy commonly received by children to treat conditions such as ear or throat infections, termed pulsed antibiotic therapy (PAT), using a non-obese diabetic (NOD) mouse model.
The investigators found that PATtreated male NOD mice had a higher incidence of T1DM than control mice, and also had increased inflammation in pancreatic islets. The PAT-treated mice also had reduced phylogenetic diversity in the gut microbiota compared with control mice. Additionally, a reduction in the number of regulatory $\mathrm{T}$ cells and type $17 \mathrm{~T}$ helper cells was found in the intestinal lamina propria of PATtreated mice, which might promote an autoimmune response.

Importantly, a number of metabolites linked to inflammation and T1DM were also upregulated in PAT-treated NOD mice compared with control mice, such as fatty acids and branched-chain amino acids. Furthermore, the expression of genes involved in the cholesterol biosynthesis pathway was higher in PAT mice than controls.

"In making decisions about individual patients, doctors must weigh the benefits and possible cost of treatments," concludes Blaser. "We already know that antibiotics are substantially overused in children. As evidence accumulates about potential new costs of antibiotic treatment, doctors must keep those in mind in making their decisions."

Charlotte Ridler

ORIGINAL ARTICLE Livanos, A. E. et al.

Antibiotic-mediated gut microbiome perturbation accelerates development of type 1 diabetes in mice. Nat. Microbiol. http://dx.doi.org/10.1038/ nmicrobiol.2016.140 (2016)

FURTHER READING Cox, L. M. \& Blaser, M. J. et al. Antibiotics in early life and obesity. Nat. Rev.

Endocrinol. 11, 182-190 (2015)

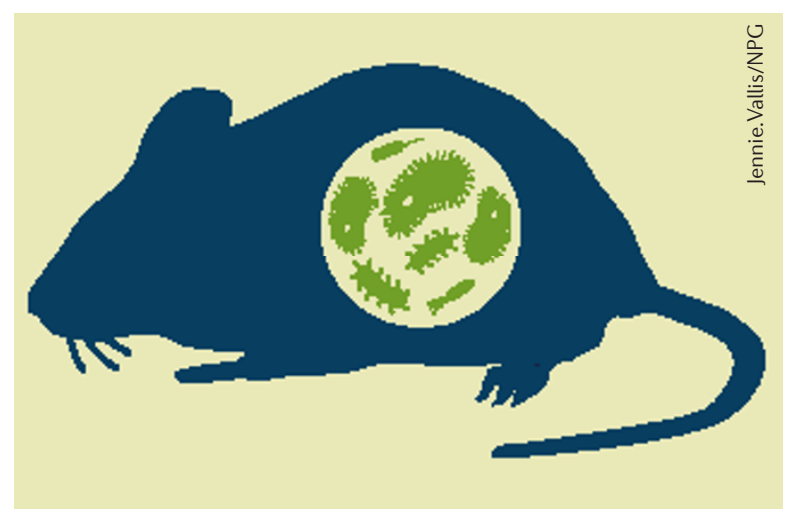

